\title{
Intraocular medulloepithelioma
}

INSERM

\section{Source}

INSERM. (1999). Orphanet: an online rare disease and orphan drug data base. Intraocular medulloepithelioma. ORPHA:268139

Intraocular medulloepithelioma is a rare eye tumor characterized by a white, gray or yellow-colored cystic mass that arises from the primitive neuroectodermal, nonpigmented epithelium of the ciliary body, or occasionally from the optic nerve, optic disc, retina or iris. Typically it has a benign clinical course with good prognosis and generally presents with childhood onset of poor vision and pain, glaucoma, and/or cataract. Leukocoria, exotropia, exophthalmos, strabismus, epiphora, change in eye color, hyphema, and raised intraocular pressure are also remarkable manifestations. 